\title{
CONFERENCE REPORT: INSPIRE SPECIAL EVENT - INSPIRING STUDENTS TO GET INVOLVED WITH DENTAL RESEARCH
}

The recent one-day conference, INSPIRE, was the first of its kind: a national undergraduate research event with the eponymous aim to inspire dental students to engage in research. It was made possible by a grant from the Academy of Medical Sciences, with funding matched by King's College London Dental Institute, the host institution. The grant was awarded to Drs Helen Petersen and Rupert Austin, with the support of Professors Dianne Rekow, Mike Lewis and Paul Speight, who all recognise the importance of encouraging budding dentists to engage with research and dental academia.

The Deans of all UK dental schools were invited to select five undergraduate students who all were given the opportunity to present their research on the day. It was intriguing to see the wide array of topics, from oral health in prisons to patterns of palatine rugae.

The conference involved talks from internationally-recognised dental academics as well as workshops on how to progress in academia. My highlights were listening to Professors Dianne Rekow, Helen Whelton and Joanna Zakrzewska describing their very different paths to reach the extraordinary positions that they now hold, with the shared, resounding message of 'don't give up', as well as placing an emphasis on the important role of female dental academics.

It was a fantastic event that expanded my knowledge with helpful advice, and definitely inspired me to pursue more research myself. All the new 'INSPIRE student Research Champions' will be disseminating the energy and enthusiasm to their respective schools by organising their own follow-up research events - those who are interested should contact their Dean to find out more!

Report by Catherine Liu. Fourth year dental student, King's College London

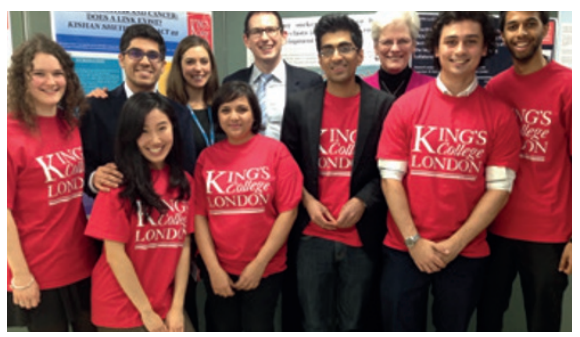

The King's College London INSPIRE team; (left to right) back row: Anna Beaven, Ashvin Babbar, Dr Saoirse 0'Toole, Dr Rupert Austin, Professor Dianne Rekow, Kishan Sheth; front row: Catherine Liu, Anisha Gupta, Ajay Mehta, Thomas Gill.

\section{BOOK REVIEW

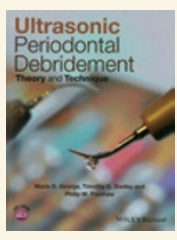 \\ ULTRASONIC PERIODONTAL DEBRIDEMENT: THEORY AND TECHNIQUE \\ Marie D. George, Timothy G. Donley and Philip M. Preshaw \\ Wiley-Blackwell \\ price $€ 44.99$ pp 232 \\ ISBN 9781118295458}

Ultrasonic Periodontal Debridement: Theory and Technique covers a range of topics condensed into 210 pages with clear-cut information, beautiful diagrams, updates and supported evidence to suit an audience from undergraduate to well experienced practitioners. It also reviews and compares historic to modern methods of periodontal debridement from manual instrumentation and ultrasonic instrumentation to laser energy.

In a total of eight chapters the authors detail everything from pathophysiology to practical recommended tricks of the trade. Helpfully, the margin has staggering blocks of colour per chapter making it easy to flick through and locate information.

It provides a common-sense approach with simple language that gets straight to the point. This makes it perfect for a quick brush-up or as preparations for those pesky exams. The use of headings nicely separates the text, making it stress-free to skip to the relevant sections.

Scientific peer-reviewed publications can be found in the reference section provided at the end of each chapter for further reading and supportive evidence.

This book has been proficiently designed with clarity and the latest evidence, making it of excellent value to every clinician's library - from undergraduate students and hygiene therapists to experienced general dental practitioners. 